\title{
Psychological Contract Theory Relation To Organizational Citizenship Behavior (OCB) Of Flight Attendants
}

\author{
Teguh Setiawan Wibowo \\ STIE Mahardhika Surabaya, Surabaya, Indonesia \\ * Corresponding author: \\ Email: teguh10setiawan@gmail.com
}

\begin{abstract}
.
In service organizations such as airlines, flight attendants as one of the components that play a direct role in serving the needs of passengers during flights are required to work independently without supervision and have confidence in carrying out job demands since they are accepted as employees. The agreement formed between the flight attendant and the airline is the initial motivation and trust given by the airline to flight attendants as employees known as psychological contracts. A high psychological contract with a reciprocal relationship where the flight attendant's expectations are fulfilled by the airline will make the flight attendant feel valued for her work and empowered. This feeling raises the motivation of flight attendants as employees to be more active by showing $O C B . O C B$ is the behavior of flight attendants as individuals voluntarily outside of their formal job descriptions to support the advancement of the airline where they work. In this article, psychological contracts are an important factor in the growth of OCB in flight attendants, such as arriving to work early, helping coworkers or new employees who are experiencing difficulties, and contributing more to activities organized by airlines.
\end{abstract}

Keyword: $O C B$, psychological contract

\section{INTRODUCTION}

The airline as an organization wants the business or business it is running to be successful in the face of very tight competition in the aviation world. This success does not only come from the airline's hard work but the business support of the flight attendants as employees who also work in improving the progress of the airline as an organization.Flight attendants as employees play an important role in increasing the effectiveness of airlines as organizations (Luthans, 2011). This shows that the key to the success of an airline as an organization is human resources, in this case the flight attendants who work in carrying out their productivity at the airline. The role of flight attendants as human resources in airlines is seen as the highest form of ability to carry out tasks and functions that cover all activities and activities of airlines as organizations (Haryati, 2012). As an individual, flight attendants are expected to carry out certain roles as determined by their job descriptions and airline expectations.OCB (Organizational Citizenship Behavior) of a flight attendant is a flight attendant's behavior as an employee in an airline that is carried out voluntarily outside a predetermined job description or it can be said as an extra role performance that is separate from in-role performance with the aim of improving the airline's performance progress.

OCB is also referred to as functional, extra-role, prosocial behavior that directs flight attendants as individuals, groups or airlines as organizations (Dyne, 1995 in Singh and Singh, 2010). OCB flight attendants are free, which indirectly and explicitly get expectations from the formal reward system, and which will overall encourage the effectiveness of the existing functions of the airline. OCB flight attendants are said to be free and voluntary because this behavior is not required to be in the job description which is clearly required under the contract that has been agreed with the airline where the flight attendant works and is considered a personal choice (Saleem and Amin, 2013). OCB of a flight attendant involves several behaviors including the behavior of a flight attendant who helps coworkers who look difficult and need help because they are still not used to working as a flight attendant, volunteer to do extra tasks outside of a flight attendant's responsibility, and obey the rules set by the flight attendant. is at work. This OCB behavior also illustrates the added value of flight attendants and initiatives that come from flight attendants as individuals 
which are not related to the airline's formal reward system, but in aggregate increase the airline's effectiveness. This indicates that the OCB of a flight attendant is not included in the job requirements or job description of a flight attendant so that if it is not displayed, it will not be punished (Sarmawa et al., 2015).

In the work environment at airlines, the presence of OCB stewardess is the impact of the beliefs and perceptions of flight attendants as individuals towards airlines in fulfilling good reciprocal relationships as employees. This behavior arises because the flight attendant feels as part of an airline that has a sense of satisfaction being able to do something more than the airline wants (Saleem and Amin, 2013). One of the reasons that support flight attendants showing OCB at an airline where they work is the impact of psychological contract fulfillment. Psychological contract is a set of unwritten expectations between flight attendants as employees and the airline (or those who represent it such as airline management) where these expectations are reciprocal in a work relationship. Airlines provide access in the form of facilities and career support as well as competitive rewards. On the other hand, flight attendants in carrying out their duties use their various abilities in a sustainable manner, increase work productivity, and volunteer extra effort for the advancement of airlines (Mathis and Jackson, 2006). This shows that the fulfillment of a high psychological contract by airlines to flight attendants as an employee will create a behavior called OCB where this behavior will make a flight attendant want to work beyond the job description or do more than just formal tasks, providing performance that exceeds expectations and OCB good flight attendants usually perform better than other flight attendants in an airline.

\section{THEORETICAL BASIS}

According to Davis (1985), psychological contract as a condition of employee psychological involvement with the company. In a psychologically fair contract, the contribution that individuals are willing to make will be perfectly related to what the organization wants to receive and similarly what the organization is willing to give will be totally related to what the individual is expected to receive. When the amount of congruence between what each party is expected to give and receive in the contract is equal to or greater than what is expected, employee commitment to the organization will increase. Argyris (1960) views the psychological contract as an implicit understanding between a group of employees and the management of the organization and the relationship develops in such a way that employees will exchange higher productivity and lower complaints in exchange for acceptable wages and job security (Taylor and Tekleab 2004). Argyris (1960) believes that employees will perform at a higher level if the organization does not interfere too much with the rules of the employee group and in return employees will respect the organization's right to develop. The characteristic that determines the first explicit conceptualization of this psychological contract is by viewing it as an exchange of real and specific resources, especially economic resources that have been agreed upon by both parties (employees and organizational management) that allow the fulfillment of the needs of each party.

Furthermore, the exchange between the two parties (employees and the organization) needs to provide mutual satisfaction so that the working relationship can continue (Roehling, 1996).Levinson et al (1962) define the psychological contract as consisting of shared expectations between an employee and the organization and these expectations arise from unconscious motives. While highlighting the role of reciprocity and the anticipated satisfaction effect of expectations, the emphasis on meeting needs in particular creates relationships in which employees will seek to meet organizational needs if the organization meets employee needs. Thus, employees and organizations have strong expectations of each other and it is the anticipation of meeting those expectations that motivates both parties to continue the working relationship.Schein (1965) states a definition of the psychological contract that is similar to that of Levnson et al (1962), where Schein places considerable emphasis on matching expectations between employees and organizations. Matching expectations and their fulfillment is very important to achieve positive results such as job satisfaction, commitment, and good performance. Consistent with this statement, Schein (1965) highlights the importance of understanding both employee and organizational perspectives and discusses how organizations can express organizational psychological contracts through culture.In Guest et 
al's (1996) psychological contract model, the benefit of undertaking a progressive set of HRM (Human Resource Management) practices is to create a positive psychological contract.

This must be taken seriously because it is closely related to employees feeling valued and part of the organization, increasing employee commitment to the organization, providing motivation to improve employee performance, higher employee satisfaction, and better working relationships or the creation of welfare for employees. HRM practices such as providing learning opportunities, training and development, focusing on job security, promotion and career, minimizing status differences, fair reward system, comprehensive communication, and the process of involving all employees in contributing will create a positive psychological contract. The steps needed to develop a positive psychological contract are setting expectations during the recruitment program and the training period, having communication and agreeing on expectations to become part of what is implied in good performance management practices, adopting a policy of transparency over policies and good management decision making. because it affects employees, and generally treats individuals as stakeholders (involved) and relies on cooperative consensus rather than coercion.Conway and Briner (2005) emphasize that the psychological contract aspect refers to beliefs about organizational promises to employees for their contributions to the organization such as wages, promotion opportunities, training, and increased welfare. According to De Vos (2002), the psychological contract includes aspects of the good working relationship that is carried out by the company to employees and employees to the company. The organization promises employees in terms of:

a. Career development

Offers the possibility for development and promotion within the organization such as job training provided by the organization and being appointed as permanent employees or promotions.

b. Job Offers (Job Content)

Offers interesting and challenging job content such as work where employees can use their capacities.

c. Social environment

Offers a pleasant work environment such as good communication between co-workers, good cooperation in groups both towards superiors and fellow coworkers.

d. Finance

Compensation offers appropriate compensation such as remuneration commensurate with the demands of the job

e. Balance with employee personality

Offer respect and understanding for the employee's personal situation such as flexibility in working hours and understanding of the employee's personal circumstances

Meanwhile, employee promises as a form of reciprocity are as follows:

a. Business or Performance Performance

Willingness to work better for the advancement of the organization by improving work performance both quantitatively and qualitatively and being able to work together with leaders and fellow co-workers

b. Flexibility

Willingness to be flexible in carrying out the work that needs to be done such as working overtime

c. Loyalty

Willingness to work longer hours for the organization by not accepting every job offer that comes along and working for the organization for at least a few years.

d. Well behaved

Willingness to behave well towards the organization such as not revealing confidential and important organizational information and being honest when dealing with resources and budgets

e. Availability

Willingness to maintain availability status at an acceptable level, such as being willing to take further education and skills if needed by the organization.

So, it can be concluded that the psychological contract aspect refers to the reciprocity between the organization and employees. Employees have confidence in the things promised by the organization, both in 
terms of fairness, salary provision, clarity of work status, employee welfare, and clear career advancement. The organization also expects employees to always contribute to the progress of the organization.Bateman and Organ (1983) are the originators and users of the term OCB (Organizational Citizenship Behavior). Furthermore, Organ (1988) defines OCB as individual behavior that is not explicitly or indirectly recognized by the formal reward system and this behavior plays an important role in the functioning and effectiveness of the organization. The behavior in question is the behavior of individuals voluntarily helping and directing coworkers who are having difficulties at work. The individual does so without any explicit or implied rewards. Organ (1997) emphasizes that voluntary behavior in question leads to behavior that contributes to the maintenance and enhancement of the psychological social context that supports task performance and organizational effectiveness.

Organ, Podsakoff, and Mackenzie (2006) define OCB as a form of employee initiative and choice behavior that is not directly recognized in awarding but can increase the effectiveness of organizational functions. Luthans (2007) also defines OCB as employee choice behavior and individual initiative, not related to the organization's formal reward system but increasing organizational effectiveness. In line with Organ et al, Robbins and Judge (2016) define OCB as an individual's independent behavior that is not from the formal job requirements of employees and contributes to the psychological and social environment in the workplace. Based on some of these terminology, it can be concluded that OCB is an initiative, free, and spontaneous behavior of employees who are outside their obligations and are not rewarded by the organization, but can increase the effectiveness of organizational functions and contribute to the psychological and social work environment in the workplace.

Several factors that influence the emergence of OCB (Organizational Citizenship Behavior) in individuals include:

\section{Job satisfaction}

Barling and Cooper (2008) state that job satisfaction is consistently identified as one of the strongest factors influencing OCB. Sager and Brown (in Yadav and Punia, 2013) state that individuals who are more satisfied with their jobs will be more likely to engage in OCB and these results show a decreasing tendency to look for other jobs.

2. Personality

Barling and Cooper (2008) stated that individuals with certain dispositional personality aspects such as agreeableness and conscientiousness can predict OCB in various settings. Robbins and Judge (2011) stated that individuals tend to be more obedient and follow the rules, do not experience accidents, and are more satisfied with their work so that they contribute to organizational performance by showing OCB. In addition, positive and negative affectivity was identified as a significant predictor of OCB personality, although the effect was weak (Barling and Cooper, 2008).

3. Organizational Justice

Research conducted by Tziner and Sharoni (2014) shows the results that organizational justice positively affects OCB. Individuals who perceive their workplace to be fair will show higher OCB manifestations among employees who perceive that the organization and its leaders treat it fairly and vice versa (Tziner and Sharoni, 2014).

4. Spirituality at work

Ghorbanifar and Azma (2014) stated that spirituality in the workplace has a positive significant effect on OCB. Individuals who have a perception of spirituality at work will show extra role behaviors, expressions of calm, and inner life satisfaction and the blessings of working so that it will encourage the emergence of OCB (Makiah, Asmony, and Nurmayanti, 2018).

5. Psychological contract

Petersitzke (2009) states that one of the factors that influence the emergence of OCB is the psychological contract. Robinson and Morrison (in Petersitzke, 2009) found that psychological contracts predict OCB and indicate the direction of a causal or reciprocal relationship. Rousseau and McLeans Parks and Van Dyne et al (in Abdullah, 2017) state that the fulfillment of a psychological contract can 
affect an individual's OCB. Meanwhile, the violation of the psychological contract can reduce the individual's contribution.

6. Psychological empowerment

Barling and Cooper (2008) state that psychological empowerment allows proactive behavior that can lead to higher work effectiveness. Wat and Shaffer (in Barling and Cooper, 2008) found that different dimensions of empowerment were related to various dimensions of OCB.

According to Nunkpit (2016), flight attendant is a profession that has high values, has high integrity, and has a mission of service and safety. Stewardess is the ideal of many people who want a prestigious job. According to Hutagaol (2013), flight attendants have the following goals:

a. carry out service duties in accordance with aviation security rules, including security in the aircraft cabin during flights both during normal and emergency conditions.

b. monitor and maintain order in the cabin and prevent passenger actions that may cause disturbance or danger to the flight and other passengers.

c. guide passengers out of the aircraft in a very limited time in order to avoid danger if suddenly an accident occurs during takeoff and landing during emergency landing both on land and in the water.

\section{DISCUSSION}

The psychological contract is an increasingly relevant aspect of workplace relationship and wider human behavior. Descriptions and definitions of the psychological contract first emerged in the 1960s, notably in the work of organizational and behavioral theorists Chris Arhyris and Edgar Schein. The psychologycal contract is a deep and varied concept and is open to a wide range of interpretations and theoretical studies.A positive psychological contract is indicated by the expectation that the obligations between the flight attendant as an employee and the airline as an organization can be fulfilled fairly. The higher the psychological contract will lead to the consequences of Guest's (1996) psychological contract model being fulfilled where the flight attendant gets increased job satisfaction. This will make flight attendants motivated to give good performance or contribution in order to create harmony and smoothness in the progress of airlines as an organization (Alberta, 2016). Psychological contracts offered by airlines to flight attendants have a positive correlation on job satisfaction and commitment to flight attendants as employees. Job satisfaction is usually obtained from the fulfillment of the expectation aspect in the psychological contract that has been carried out by the flight attendant with the airline since the official contract has been signed.

The satisfaction is in the form of giving salary or wages that are in accordance with the demands of the job, promotion of positions for outstanding flight attendants, providing training that is in accordance with the field of flight attendants, a working environment for flight attendants who have good communication and cooperation between fellow flight attendants and with the airline management. as well as flexibility and a sense of respect by the airline where the flight attendant works. The satisfaction of a flight attendant like that will create a flight attendant OCB where the flight attendant becomes more enthusiastic and willing to devote all his abilities to work and has the desire to contribute more beyond his job description. The first factor that is thought to play a role in the high OCB of flight attendants against the airline in the psychological contract aspect is the emergence of the airline's commitment as an organization. Airline commitment of a flight attendant can be seen from the period of service. On average, flight attendants who have permanent employee status have a minimum working period of more than 3 years, some even have worked for a dozen to tens of years on an airline. The length of work taken by the flight attendant makes the flight attendant have a high individual commitment (Oktaviani and Fauziah, 2017). High individual commitment will lead to an increase in the performance of flight attendants and their positive behavior in airlines which indirectly supports the success of the airline in achieving its goals (Titisari, 2014). The second factor is the culture of the airline where the flight attendant works, which is an aspect of the social environment in the psychological contract. Airline culture also affects the increase in OCB of flight attendants because a good culture will 
create comfort for flight attendants at work and feel that the values of flight attendants are in line with the values adopted by the airline (Organ, Podsakoff and McKenzie, 2006).

Airline culture as a good organization such as morning apples, morning gymnastics, and routine activities held every year such as social service activities and bihalal activities. When viewed from these two factors, a positive or high airline psychological contract will provide an opportunity for flight attendants as individuals to show OCB in their work environment.In the psychological contract on the aspect of flexibility as a flight attendant reciprocal to the airline, flexibility behavior is also referred to as extra role behavior. This behavior is defined as behavior that seeks to benefit the airline as an organization and exceeds the expectations of the existing role. Katz and Kahn (1996) distinguish between role behavior or behavior conforming to formal role descriptions and extra role behavior or actions beyond the requirements of formal work roles. The extra-role behavior of a flight attendant as an employee arises from the feeling of being part of the airline where the flight attendant works. Thus, flight attendants carrying out certain activities on behalf of the airline where they work become the flight attendant's commitment without being formally required to do so. OCB of flight attendants being an extra role behavior does not mean that in these airlines the flight attendants are not noticed and appreciated by management or do not have an impact on formal and informal assessments of the performance of the flight attendants, but rather it affects the job evaluation of the flight attendants.

Therefore, the flight attendant as an employee who engages because the flight attendant wants it indicates that his behavior is prosocial and voluntary for the benefit of the airline.In the psychological contract aspects of good behavior, positive traits and personality shown by flight attendants as employees significantly increase the OCB of flight attendants. Psychological contracts covering the implicit expectations of flight attendants from their airlines found that motivating flight attendants as employees through satisfaction of the intrinsic need for development and a pleasant work environment led to an increase in flight attendant OCB (Nimram, 2011; Xander et al., 2011).If the flight attendant as an employee is seen from subjective perception, the career development aspect, namely the internal career in the psychological contract, affects the OCB level of the flight attendant. Differences in the work status of flight attendants as employees affect their OCB level for the airline they work for. Comparison of the OCB of permanent and non-permanent flight attendants revealed that flight attendants as contract employees have less function than flight attendants as permanent employees, although there is no difference in job descriptions between the two. Although flight attendants as contract employees are less oriented to their status, flight attendants as permanent employees or not are equally important (Chompookum and Derr, 2004; Huang, Jin and Yang, 2004; Stampler and Dyne, 2001).

When viewed from organizational justice factors and psychological contracts that affect OCB, flight attendants who feel the procedures or workload of the airline they work for are fair, flight attendants tend to be involved in the behavior of being part of the airline. Wong et al (2004) consider distributive justice and procedural justice as a previous state of trust in airlines which means that OCB of flight attendants is influenced by their trust in the airline where they work. The flight attendant as an employee will adjust to the signal or information that shows whether the flight attendant as an individual is valued or not in the work environment. This means that flight attendants feel valued if they receive fair treatment in the work environment. On the other hand, flight attendants feel unappreciated or considered inferior if the flight attendant is treated unfairly within the airline environment where they work. As a result, flight attendants as individuals feel they do not want to be involved in actions to advance the airline and reduce their sense of trust in their place of work (Tyler, 1999; Dijke et al, 2012; Lind and Tyler, 1998; Tyler and Lind, 1992).Psychological contract theory is intangible and difficult to state measurably. With a venn diagram can help describe these intangible shapes. In Venn diagrams, psychological contracts are used to represent situations and conditions in which two or more areas interact. Venn diagrams were created around 1880 by a British logician and philosopher named John Venn. Business Balls (2010) interpret the psychological contract in diagram venn. In the Venn diagram of the psychological contract, the intersection between the employee and the employer is termed a Visible Contract (VC), namely the obligation of a written employment contract. The intersection between employee - market and employer - market is termed as 
Relationship References (RR). The intersection between employee - employer - market is a Psychological Contract (PC).

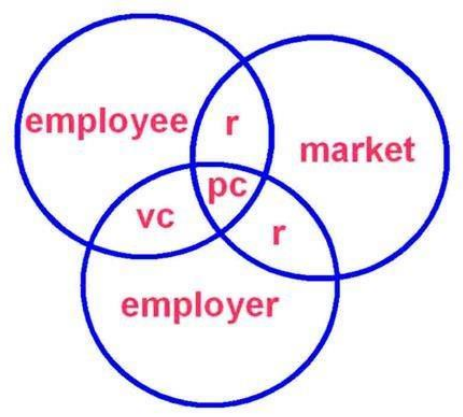

Fig 1. Psychological Contract Venn Diagram

\section{CONCLUSIONS AND SUGGESTIONS}

\section{Conclusion}

Based on the description above, it can be concluded several things as follows:

a. The high psychological contract applied by the airline will create a positive influence with the higher OCB of the flight attendant on passengers during the flight and the airline where they work. This means that the higher the level of psychological contract offered by the airline, the higher the OCB of a flight attendant for passengers and the airline where she works.

b. Fulfillment of aspects in the form of promises or expectations of flight attendants in psychological contracts offered by airlines will affect the emergence and increase of flight attendant OCB towards passengers and airlines. This means that the OCB of flight attendants appears and increases if the airline fulfills the aspects that are expected by the flight attendant in the psychological contract.

c. The high and low OCB of flight attendants in an airline is influenced by the level of fulfillment of the expectations contained in the psychological contract. With the fulfillment of a high psychological contract aspect, flight attendants as an employee will feel valued, become part of the airline, feel empowered, form a bond of trust and have job satisfaction. These feelings of flight attendants will create OCB of flight attendants towards airlines where flight attendants take initiative, freely, and voluntarily take actions that exceed job descriptions or airline expectations without being rewarded such as by arriving to work early, helping coworkers or new employees who experience difficulties or are not familiar with their job descriptions, follow and share information about airline developments, and have a more active contribution from flight attendants to activities organized by airlines.

\section{Suggestion}

a. Psychological contracts offered by airlines have a positive effect on the emergence and increase of OCB of flight attendants in the airline environment if reciprocal expectations on aspects of psychological contracts are met, especially the job satisfaction of flight attendants in carrying out their duties for passenger service during flights, feeling valued and being part of the flight attendant. the airline, the flexibility, fairness both distributive and procedural that the flight attendants get, and the trustworthiness of the flight attendant to the airline where they work so that the flight attendant feels comfortable for a long-term work contract.

b. So that the level of the airline's psychological contract is high for the OCB of the flight attendant, it would be better if the airline management paid more attention to the fulfillment of the psychological contract aspects that support the job satisfaction of the flight attendant as an employee because these aspects are closely related to the factors that influence the emergence and increase of OCB. flight attendants to take the initiative, volunteer, and be free to actively do things beyond their job descriptions to advance the airline they work for. 


\section{REFERENCES}

[1] Abdullah, R. 2017. The Effect of Organizational Commitment and Job Satisfaction on Organizational Citizenship Behavior of Employees of PT. Arminta.

[2] Asmony, T., Nurmayanti, S., and Makiah. 2018. Effect of Work Life Balance, Workplace Spirituality of Organizational Citizenship Behavior (OCB) Through Organizational Commitment as Intervening Variables (Study on Teacher Generation Y In Islamic Boarding School District West Lombok, Indonesia). International Journal of Economics, Commerce and Management United Kingdom, VI (7): 776-800.

[3] Barling, J., and Cooper, C.L. 2008. The SAGE Handbook of Organizational Behavior, Volume One-Micro Approaches. SAGE Publications Ltd.

[4] Bateman, TS and Organ, DW. 1997. Job Satisfaction and Good Soldier: The Relationship between Affect and Employee Citizenship. Academy of Management Journal.

[5] Brown, SP and Robert A. Peterson. 1993. "Antecedents and Consequences of Alessperson Job satisfaction: Meta-analysis and assessment of Causal Effect.” Journal of Marketing Research 30 (February): 63-77.

[6] Chompookum, D. and Derr, C. B. 2004. The Effects of Internal Career Orientations on Organizational Citizenship Behavior in Thailand, Career Development International. 9(4): 406-423.

[7] Conway and Briner. 2005. Understanding Psychological Contracts at Work. New York: Oxford University.

[8] Davis, K. 1985. Behavior in Organizations. Jakarta: Erlangga.

[9] De Vos, AS and Schulze, S. 2002. The Sciences and The Professions. In De Vos, AS, Strydom, H. Fouché, CB, \& Delport, CSL Research at The Grass Roots for The Social Sciences and Human Service Professions. 2nd ed. Pretoria: JL Van Schaik Publishers.

[10] Dijke, V. Marius, Cremer, D., Mayer, DM and Quaquebeke, N. 2012. When Does Procedural Fairness Promote Organizational Citizenship Behavior: Integrating Empowering Leadership Types in Relational Justice Models, Organizational Behavior and Human Decision Processes.17(2): 235-248.

[11] Dyne, LV, Cummings, LL, and Parks, JM 1995. Extra-Role Behavior: In Pursuit of Construct and Definitional Clarity. Research in Organization Behavior, 17: 215-285.

[12] Ghorbanifar, M., and Azma, F. 2014. Workplace Spirituality and Organizational Citizenship Behavior: Evidence from Banking Industry. Management Science Letters. 4: 1685-1692.

[13] Haryati, DN 2019. The Influence of Motivation and Personality on Organizational Citizenship Behavior. with Organizational Culture as Moderating Variable. Maksipreneur Journal. 9(1): 28-40.

[14] Huang, J., Jin, B. \& Yang, C. 2004. Satisfaction with Business-to-Employee Benefit Systems and Organizational Citizenship Behavior: An Examination of Gender Differencess, International Journal of Manpower. 25(2): 195-210.

[15] Hutagaol, JD, Wibowo, MA, and Santoso, TD. 2013. Comparison of Critical Path Method (CPM), Precedence Diagram Method (PDM), and Line of Balance (LOB) Against Repetitive Projects. Journal of Civil Engineering Works. 2(1): 205-227.

[16] Katz, D. and R. Kahn. 1996. The Social Psychology of Organizations. New York: Wiley Publishing Co.

[17] Levinson, H., Price, CR, Munden, KJ and Solley, CM. 1962. Men, Management and Mental Health. Harvard University Press, Cambridge, MA.

[18] Lind, EA and Tyler, TR 1988. The Social Psychology of Procedural Justice. NY: Plenum. Translated into Japanese, Tokyo: Tuttle-Mori Publishing.

[19] Luthans, F., and Youssef, CM. 2007. Emerging Positive Organizational Behavior. Journal of Management. 33(3): 321-349.

[20] Luthans, Fred. 2011. Organizational Behavior. Yogyakarta: Penerbit Andi.

[21] Mathis, RL and JH Jackson. 2006. Human Resource Management: Human Resource Management. Dian Angelia's translation. Jakarta: Salemba Empat.

[22] Nimram, U. 2011. Relationships between Individual Characteristics of Employees and Organizational Climate with Organizational Citizenship Behavior (OCB), Journal of Basic and Applied Scientific Research. 1(11): 2310-2313.

[23] Nukpit, F. 2016. Alloys Successfully Passed the Stewardess Selection. Yogyakarta: Araska

[24] Oktaviani, A., Fauziah, N. 2017. The Relationship Between Psychological Contracts and Organizational Citizenship Behavior in Semarang Post Office Employees. Journal of Empathy. 6(1): 21-26.

[25] Organs, D. W 1988. Organizational Citizenship Behavior: The Good Soldier Syndrome. Lexington, MA: Lexington Books. 
[26] Organ, D. W 1997. Organizational Citizenships Behavior: It's Construct Cleanup Time. Human Performance. 10(2): 85-97.

[27] Organ, D. W., Podsakof, M.P., and MacKenzie, B. S. 2006. Organizational Citizenship Behavior. USA: Sage Publications, Inc.

[28] Petersitzke, M. 2009. Supervisor Psychological Contract Management. Springer Science \& Business Media.

[29] Robbins, S.P, and Timothy A. Judge. 2016. Organizational Behavior. Edition 16. Jakarta: Salemba Empat.

[30] Rousseau, D. M and Parks, I. M 1993. The Contracts of Individuals and Organizations. Research in Organizational Behavior. 15: 41-43.

[31] Sager, Jeffrey K., 1994, A Structural Model Depecting Salespeople's Job Stress. Journal of the Academy of Marketing Science, 22 (Winter): 74-84.

[32] Saleem, S. and Amin, S. 2013. The Impact of Organizational Support for Career Development and Supervisory Support on Employee Performance: An Emperical Study from Pakistani Academic Sector. European Journal of Business and Management. 5(5): 194-207.

[33] Sarmawa, I. W. G. 2015. Commitment \& Competency as a Predictor and Its Effect on The Performance. A Study of Private Vocational High Schools in Klungkung Recency Bali. International Journal of Economics, Commerce and Management United Kingdom, Vol. III.

[34] Singh, A. K, and Singh, A. 2010. Career Stage and Organizational Citizenship Behavior Among Indian Managers. Journal of the Indian Academy of Applied Psychology, 36(2): 268-275.

[35] Stamper, CL and Dyne, LV 2001. Work Status and Organizational Citizenship Behavior: A Field Study of Restaurant Employees. Journal of Organizational Behavior. 22(5): 517-536.

[36] Titisari, P. 2014. The Role of Organizational Citizenship Behavior. Bandung: Media Discourse Partners.

[37] Tyler, TR and Lind, EA. 1992. A Relational Model of Authority in Groups, Advances in Experimental Social Psychology. 25(2): 115-191.

[38] Tyler, TR, Huo, YJ and Lind, EA 1999. The Two Psychologies of Conflict Resolution: Differing Antecedents of Pre-Experience Choices and Post-Experience Evaluations, Group Processes and Intergroup Relations, 2(2): 99-118.

[39] Tziner, A., and Sharoni, G. 2014. Organizational Citizenship Behavior, Organizational Justice, Job Stress, and Work Family Conflict: Examination of Their Interrelationships with Respondents from A Non-Western Culture. Journal of Work and Organizational Psychology. 30(1): 35-42.

[40] Wong, CS, Law, KS, and Wong, P. M 2004. Development and Validation of a Forced Choice Emotional Intelligence for Chinese Respondents in Hong Kong, Asia Pacific Journal of Management. 21(4): 535-559.

[41] Xander D. L, Blomme R. J, and Bal, P. M. 2011. Psychological Contract and Organizational Citizenship Behavior: A New Deal for New Generations? In Joseph S. Chen (ed.). Advances in Hospitality and Leisure, Cambridge: Emerald Group Publishing Limited, pp.109-130.

[42] Yadav, P., and Punia, B. K. 2013. Organizational Citizenship Behavior: A Review of Antecedence, Correlates, Outcomes, Future Research Directions. IJHPD. 2(2). 